\title{
Erratum zu: Offenheit in der IT: Herausforderung und Chance zu Veränderungen
}

\section{Matthias Knoll}

Angenommen: 8. März 2021 / Online publiziert: 29. März 2021

(C) Der/die Autor(en) 2021

\section{Erratum zu: \\ HMD 2021 \\ https://doi.org/10.1365/s40702-021-00712-4}

In der Originalveröffentlichung wurde versehentlich eine unvollständige und falsche Autorenreihenfolge genannt.

Statt (Anke 2021) muss die Zitation korrekt heißen (Ehrlich et al. 2021) und im Literaturverzeichnis entsprechend:

Ehrlich, T., Richter, D., Meisel, M. et al. Self-Sovereign Identity als Grundlage für universell einsetzbare digitale Identitäten. HMD (2021). https://doi.org/10.1365/ s40702-021-00711-5

Der Autor bittet das Versehen zu entschuldigen.

Open Access Dieser Artikel wird unter der Creative Commons Namensnennung 4.0 International Lizenz veröffentlicht, welche die Nutzung, Vervielfältigung, Bearbeitung, Verbreitung und Wiedergabe in jeglichem Medium und Format erlaubt, sofern Sie den/die ursprünglichen Autor(en) und die Quelle ordnungsgemäß nennen, einen Link zur Creative Commons Lizenz beifügen und angeben, ob Änderungen vorgenommen wurden.

Die in diesem Artikel enthaltenen Bilder und sonstiges Drittmaterial unterliegen ebenfalls der genannten Creative Commons Lizenz, sofern sich aus der Abbildungslegende nichts anderes ergibt. Sofern das betreffende Material nicht unter der genannten Creative Commons Lizenz steht und die betreffende Handlung nicht nach gesetzlichen Vorschriften erlaubt ist, ist für die oben aufgeführten Weiterverwendungen des Materials die Einwilligung des jeweiligen Rechteinhabers einzuholen.

Weitere Details zur Lizenz entnehmen Sie bitte der Lizenzinformation auf http://creativecommons.org/ licenses/by/4.0/deed.de.

Die Online-Version des Originalartikels ist unter https://doi.org/10.1365/s40702-021-00712-4 zu finden.

M. Knoll $(\bowtie)$

Hochschule Darmstadt, Haardtring 100, Darmstadt, Deutschland

E-Mail: matthias.knoll@h-da.de 